Original Article

\title{
FETAL HEAD ANTHROPOMETRY: A CROSS- SECTIONAL STUDY FROM KUMAUN REGION
}

\author{
Anamika Jaiswal*, Ankit Kaushik**, AK Singh* \\ *Department of Anatomy, Government Medical College, Haldwani, Uttarakhand, India \\ **Department of Pathology, Government Medical College, Haldwani, Uttarakhand, India
}

\begin{abstract}
Introduction: Biparietal diameter (BPD) and head circumference $(\mathrm{HC})$ are important for estimating gestational age (GA), monitoring fetal growth and to rule out congenital abnormalities. Western references using $\mathrm{HC}$ and BPD can lead to erroneous GA estimation, therefore regional reference is required.
\end{abstract}

Aim: To measure $\mathrm{HC}$ and BPD in fetus at different GA, their relationship with GA and comparison of $\mathrm{HC}$ and BPD with expected $\mathrm{HC}$ and BPD by "Hadlock's formula".

Material \& Methods: CRL, HC and BPD were measured in 72 fetuses. Mean and standard deviation of $\mathrm{HC}$ and BPD were calculated for all fetuses and across three trimesters. The correlation of $\mathrm{HC}$ and $B P D$ with GA was calculated and $p$ value was derived. Hadlock's $\mathrm{HC}$ and BPD were calculated for the gestational age. The observed HC and BPD in the study were compared with the Hadlock's value to find out any difference between them

Results: The mean $\mathrm{HC}$ of fetuses was $23.7 \pm 8.58 \mathrm{~cm}$. The mean $\mathrm{HC}$ in first trimester was $6.3 \mathrm{~cm}$, $15.13 \mathrm{~cm}$ in second trimester and $30.8 \mathrm{~cm}$ in third trimester. The mean $\mathrm{HC}$ of fetuses according to Hadlock's formula was $23.72 \pm 8.80 \mathrm{~cm}$. The mean Hadlock's HC in first trimester was $5.6 \mathrm{~cm}, 14.92$ $\mathrm{cm}$ in second trimester and $31.12 \mathrm{~cm}$ in third trimester. The mean BPD in the studied fetuses was 5.92 $\pm 2.24 \mathrm{~cm}$. The mean BPD in first trimester was $1.7 \mathrm{~cm}, 4.8 \mathrm{~cm}$ in second trimester and $7.8 \mathrm{~cm}$ in third trimester. The mean Hadlock's BPD was $6.33 \pm 2.41 \mathrm{~cm}$. The mean Hadlock's BPD in first trimester was $1.6 \mathrm{~cm}, 4.4 \mathrm{~cm}$ in second trimester and $8.3 \mathrm{~cm}$ in third trimester.

The mean $\mathrm{HC}$ of fetuses were nearly equal to mean Hadlock's formula, while BPD of the study fetuses was less than mean Hadlock's BPD. Both HC and BPD measured at different GA showed increase, with increase in GA and strong positive correlation and statistically significant association.

Conclusion: This study had shown that while $\mathrm{HC}$ is nearly equal to Hadlock's reference, BPD was less than Hadlock's for GA, reflecting need of local reference data for accurate fetal age estimation.

Keywords: Head circumference, biparietal diameter, fetus.

\section{INTRODUCTION}

Antenatal measurement of multiple fetal parameters is important for assessing fetal wellbeing and monitoring intrauterine growth. Head circumference $(\mathrm{HC})$ and biparietal diameter (BPD) are routinely measured by ultrasound in second and third trimester of pregnancy [1]. BPD and HC are important for estimating gestational age (GA), monitoring fetal growth and to rule out congenital abnormalities. Various ultrasound-based formulas using $\mathrm{HC}$ and BPD are available for GA estimation but they are mostly western based data but variations exist based on races, ethnic group and nutritional status, like African babies have higher HC and Indian babies have low HC [2].

Address for Correspondence:

Dr Ankit Kaushik, Assistant Professor, Department of Patholgy, Government Medical College, Haldwani, Nainital, Uttarakhand. 263139, India.

Mob: 9953816240 Email: kaushikankit1983@gmail.com 
World Health Organization Multicentric Growth Reference Study (MGRS) provides set of reference growth curve chart for fetal development but large studies have shown marked difference in HC among national and ethnic group. Therefore, use of single HC reference is not justified. Statistical data from local population is urgently needed for accurate assessment of GA [3].

Ultrasound-based studies measuring HC and BPD are found from India [4,5], however anthropometric studies are limited, if any from Kumaun region, Uttarakhand. This anthropometric study provides a unique opportunity for measurement of HC, BPD at different GA and their relationship with GA. We also compared measured $\mathrm{HC}$ and BPD with "Hadlock's formula" values to observe the difference if any exist among the two.

\section{MATERIAL AND METHODS}

This cross-sectional study was done in Department of Anatomy, Government Medical College, Haldwani, Nainital, Uttarakhand. Study involved 72 spontaneously aborted human fetuses from 10 to 42 weeks of gestation. The menstrual GA was taken from the history. Inclusion criteria were spontaneously aborted fetus and known menstrual GA. Exclusion criteria were congenital abnormality involving head, face and neck; unsure menstrual GA, intrauterine growth retardation and poor nutritional status.

All measurements were taken with help of a flexible, non-stretchable metal ruler. The measurements were recorded in centimeters $(\mathrm{cm})$, with values rounded off to first decimal place. HC was taken as widest possible circumference of head from broadest part of forehead above eyebrow, above the ear to most prominent part in posterior head above occiput [6]. BPD was measured from greatest transverse diameter of the head, which extends from one parietal boss to the other.

Three group were divided among fetuses according to GA in to first, second and third trimester. First group comprises of GA up to 12 weeks, second trimester with fetuses from 13 weeks to 26 weeks of GA and last trimester above 26 weeks. Mean and standard deviation of CRL, HC and BPD were calculated for all fetuses and across three different trimesters. The Pearson correlation coefficient of $\mathrm{CRL}, \mathrm{HC}$ and BPD with GA was calculated and $p$ value was derived to see whether $\mathrm{CRL}, \mathrm{HC}$ and BPD had statistically significant association with GA. Hadlock's HC and BPD were calculated for the gestational age and the observed HC and BPD in the study were compared with the Hadlock's value [7] to find out if any difference between them exist. Graph was plotted for different value of CRL, HC and BPD against GA to show their relations.

\section{OBSERVATIONS AND RESULTS}

Out of a total of 72 fetuses, 38 were male fetuses and 34 were female fetuses. There were 3 fetuses in first trimester, 32 in second trimester and 37 in third trimester. The mean CRL of male and female fetuses were $23.62 \pm 8.00 \mathrm{~cm}$ and $22.68 \pm 7.02 \mathrm{~cm}$, respectively.

The mean $\mathrm{HC}$ of fetuses was $23.7 \pm 8.58 \mathrm{~cm}$ (Table 1). The mean $\mathrm{HC}$ in first trimester is $6.3 \mathrm{~cm}, 15.13$ $\mathrm{cm}$ in second trimester and $30.8 \mathrm{~cm}$ in third trimester. The $\mathrm{HC}$ measured at different GA showed increase in head circumference with increase in GA (Fig. 1) and strong positive correlation with correlation coefficient of 0.96 and significant statistical association with GA when $p$ value less than 0.01 was considered as significant (Table 1). The mean $\mathrm{HC}$ of fetuses according to Hadlock's formula was $23.72 \pm 8.80 \mathrm{~cm}$. The mean Hadlock's HC in first trimester is $5.6 \mathrm{~cm}, 14.92 \mathrm{~cm}$ in second trimester and $31.12 \mathrm{~cm}$ in third trimester (Table 2). A graph plotted for comparing $\mathrm{HC}$ obtained for all fetuses and expected Hadlock's HC for respective GA, shows both $\mathrm{HC}$ to be nearly equal (Fig. 2). Across all three trimesters, the measured $\mathrm{HC}$ is nearly equal to expected Hadlock's HC (Fig. 3).

The mean BPD in the studied fetuses was $5.92 \pm 2.24 \mathrm{~cm}$ (Table 1). The mean BPD in first trimester is $1.7 \mathrm{~cm}, 4.8 \mathrm{~cm}$ in second trimester and $7.8 \mathrm{~cm}$ in third trimester (Table 2). The expected BPD according to Hadlock's formula was also calculated; the mean Hadlock's BPD was $6.33+/-2.41 \mathrm{~cm}$. The mean Hadlock's BPD in first trimester is $1.6 \mathrm{~cm}, 4.4 \mathrm{~cm}$ in second trimester and $8.3 \mathrm{~cm}$ in third trimester (Table 2). The BPD measured for different GA showed increase in BPD with increase in GA (Fig. 1) and showed strong positive correlation with correlation coefficient of 0.99 and significant statistical 
association when $p$ value less than 0.01 considered as significant (Table 1). A graph plotted for comparing BPD obtained for all fetuses and expected Hadlock's BPD for respective GA, shows Hadlock's BPD to be higher than measured BPD (Fig. 4). Across all three trimesters, the measured BPD is less than expected Hadlock's BPD (Fig. 5).

Table 1: Mean and standard deviation of CRL, $\mathrm{HC}$ and BPD and their correlation and $p$ value with GA

\begin{tabular}{|l|l|l|l|l|}
\hline Parameter $(\mathbf{c m})$ & Mean $(\mathbf{c m})$ & St Dev $(\mathbf{c m})$ & r value & p value \\
\hline CRL & 23.17 & 8.00 & 0.989617 & Significant \\
\hline HC & 23.7 & 8.58 & 0.959974 & Significant \\
\hline BPD & 5.92 & 2.24 & 0.994524 & Significant \\
\hline
\end{tabular}

Table 2: Mean BPD, mean Hadlock's BPD, mean HC and mean Hadlock's HC in first, second and third Trimester

\begin{tabular}{|l|l|l|l|l|}
\hline Trimester & BPD $(\mathbf{c m})$ & Hadlock BPD $(\mathbf{c m})$ & HC $(\mathbf{c m})$ & Hadlock HC $(\mathbf{c m})$ \\
\hline First & 1.73 & 1.66 & 6.3 & 5.66 \\
\hline Second & 4.12 & 4.4 & 15.13 & 14.92 \\
\hline Third & 7.83 & 8.3 & 30.8 & 31.12 \\
\hline
\end{tabular}

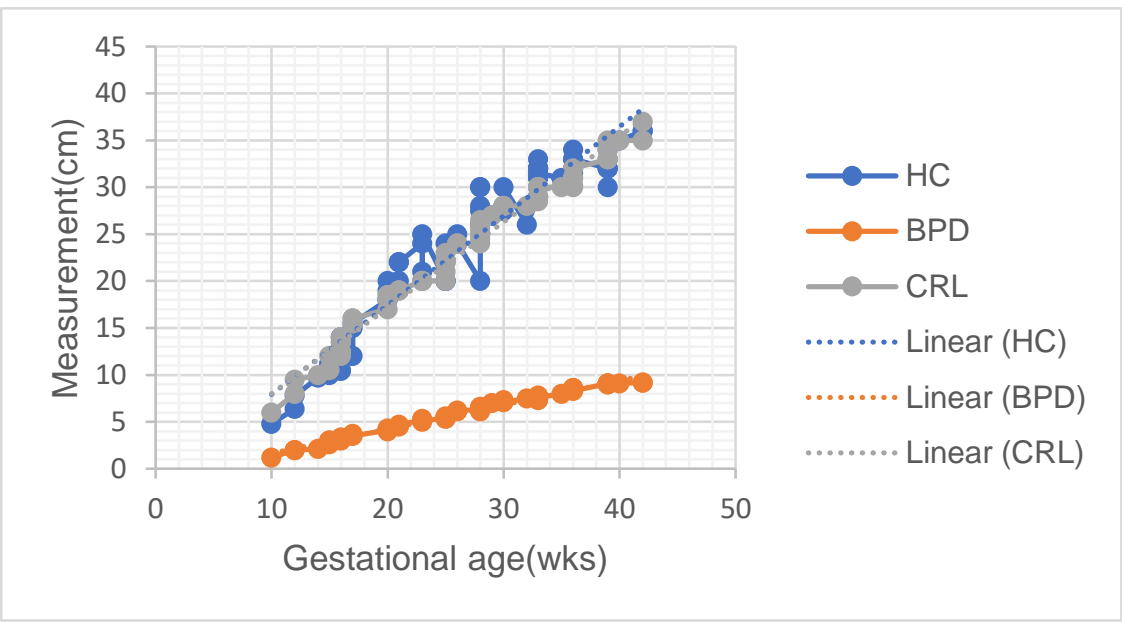

Fig. 1: HC, BPD and CRL on y axis in $\mathrm{cm}$ and gestational age in weeks on $\mathrm{x}$ axis. $C R L, H C$ and BPD increases with increase in GA

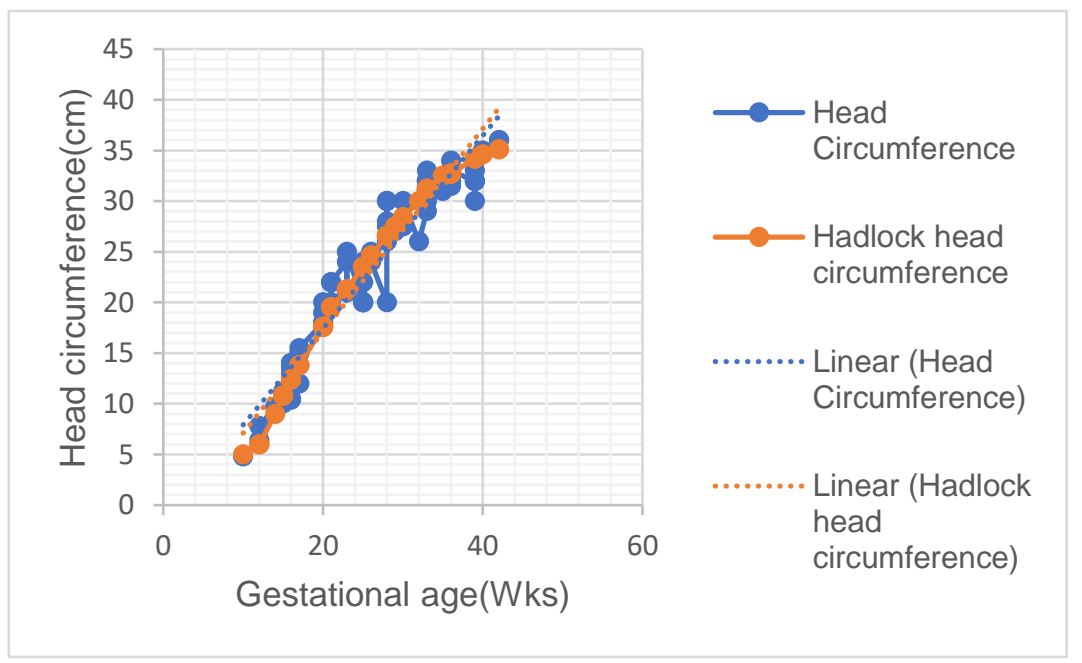

Fig. 2: HC and Hadlock's HC on y axis and gestational age on $x$ axis; both HC and Hadlock's HC are equal 


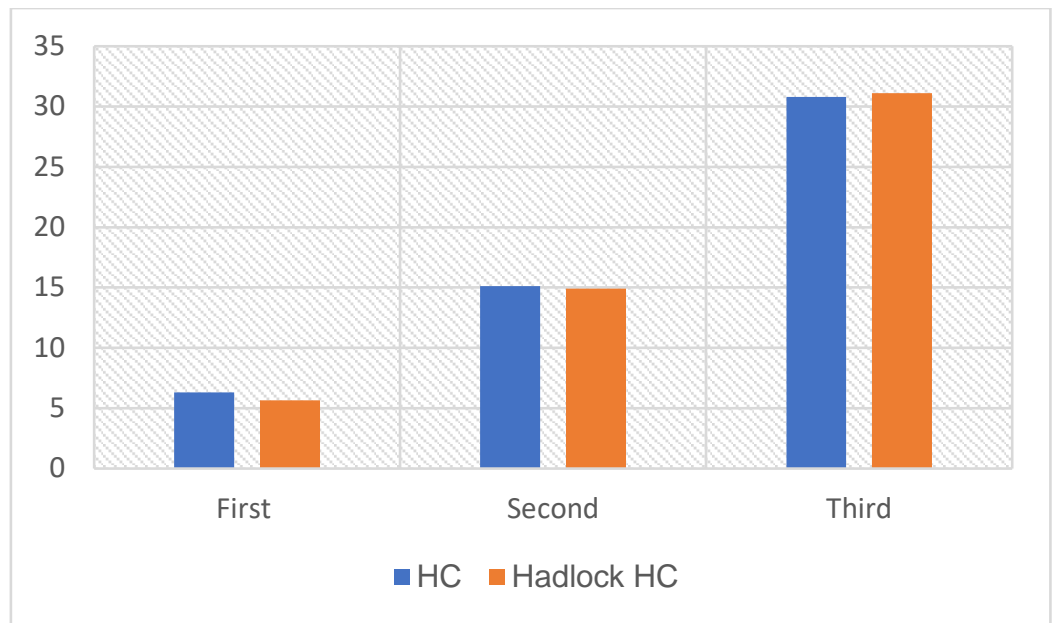

Fig. 3: Mean HC (blue) and Hadlock's HC (orange) in first, second and third trimester

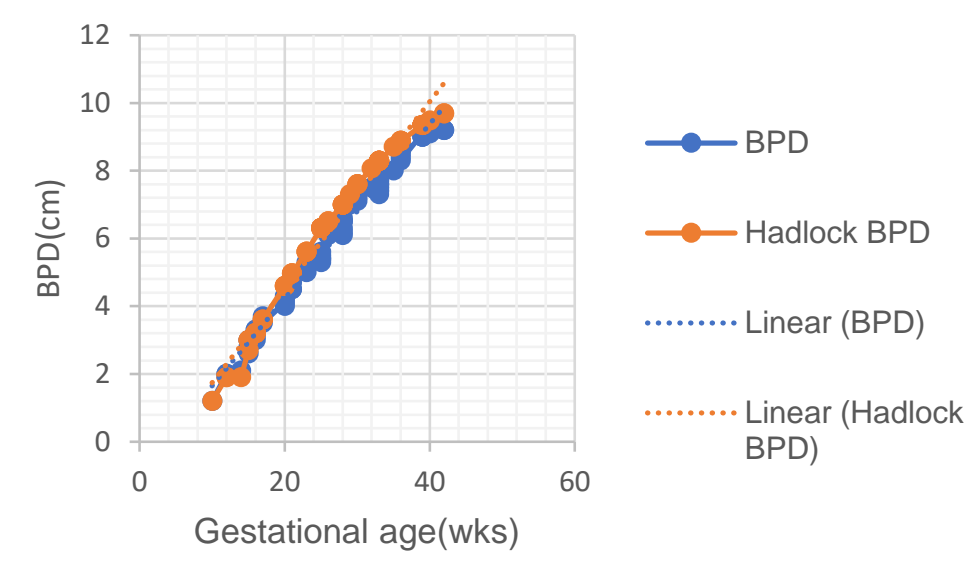

Fig. 4: BPD and Hadlock's BPD on y axis and gestational age on $x$ axis. Hadlock's BPD is higher than study BPD

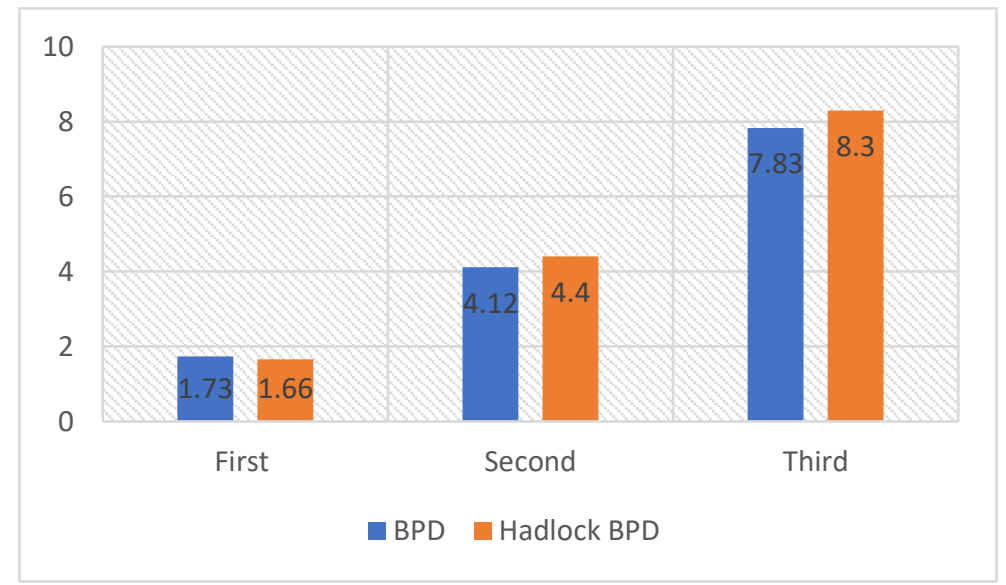

Fig. 5: Mean BPD (blue) and Hadlock's BPD (orange) in first, second and third trimester 


\section{DISCUSSION}

$\mathrm{HC}$ measurement is a surrogate marker of brain size and brain growth and integral part of Pediatric Neurological Examination [8]. Normal range of $\mathrm{HC}$ is important as marked variation in $\mathrm{HC}$ was noted among different population. Asian newborns were found to have smaller $\mathrm{HC}$ than Caucasian newborn [9]. Head size above and below two standard deviation places head into macrocephaly (large head) and microcephaly (small head). The underlying causes of macrocephaly and microcephaly may be just an anatomical cause but may signify important congenital abnormalities. Periodic antenatal ultrasound scans can detect early abnormal growth of various head parameter, helping in early detection of various congenital abnormalities affecting head [8].

Growth of fetus is different between populations. Indian babies are considered to be smaller than western population [10] but this is not proportionate for all the measurements, as a comparative study between UK and India showed birth weight and abdominal circumference to be much less in comparison to length and subscapular skinfold [11].

Gestational age estimation is based on various models that are western population based like Hadlock's (AC-HC), Woo's (AC-BPD) model, Combs (AC-HC-FL) and Hadlock-3 (AC-HC-FL) models. But directly applying western based models on Indian population can lead to higher errors on Indian population, therefore need of models based on native Indian population is essential; for that fetal head anthropometric measurement are needed [2].

Deloison et al. (2012) studied pregnancies outcomes in which the fetal $\mathrm{HC}$ was below the $5^{\text {th }}$ centile in second-trimester scan of 18,377 women. They found that $3.7 \%$ of fetuses had $\mathrm{HC}$ below the $5^{\text {th }}$ centile. They found that in comparison to fetuses with normal HC, fetuses with progressively less HC for GA have much higher chances of neurological abnormalities and associated with poor pregnancy outcome. A HC less than $5^{\text {th }}$ centile is associated with various neurological disorders. HC with $\mathrm{z}$ score below 2.5 was strongly associated with neurological and chromosomal abnormalities [12].

Abnormally large head for gestational age is associated with various obstetrical complications, due to mismatch between large fetal head and maternal pelvis leading to cephalopelvic disproportion (CPD). CPD can leads to obstructed labor, one of the leading causes of obstetrical death in developing countries and are more common in primigravidae. Fetus with large head are associated with difficult delivery leading to increasing likelihood of emergency lower segment cesarean section and assisted delivery. Other complications include shoulder dystocia, prolonged labor and signs of fetal distress. Thus, head parameters become more relevant in predicting mode of delivery and necessary steps to prevent complications [13-15].

The mean BPD in the studied fetuses was $5.92+/-2.24 \mathrm{~cm}$ and mean Hadlock's BPD was $6.33+/-2.41$ $\mathrm{cm}$. The mean BPD in first trimester is $1.7 \mathrm{~cm}, 4.8 \mathrm{~cm}$ in second trimester and $7.8 \mathrm{~cm}$ in third trimester and is found to be lower when compared to expected mean Hadlock's BPD which is $1.6 \mathrm{~cm}$ in first trimester, $4.4 \mathrm{~cm}$ in second trimester and $8.3 \mathrm{~cm}$ in third trimester (Table 2, Fig. 5). This study showed linear increase in BPD with increase in GA.

Jaiswal et al. (2015) assessed GA in local population (southern zone) of Rajasthan by measuring fetal BPD with ultrasound in pregnant females in their second and third trimester with known gestational age by last menstrual period. They found that BPD shows linear increase with increasing GA and mean BPD in Indian population is lower than western studies but correlated with Hadlock's series and they suggested that the difference is possibility due to racial, genetic, nutritional and socioeconomic factor [5].

Chan and Yeo (1991) measured BPD by ultrasound in 1442 Chinese fetuses between 17 to 40 weeks of GA and calculated the two standards of error. They compared the results with 2 standard errors of the BPD of the Caucasian fetuses. They found statistical difference between two means and the 2 standard errors and emphasized that nomogram for local regional population is needed [16].

The mean HC and Hadlock's HC for respective GA were $23.7+/-8.58 \mathrm{~cm}$ and $23.72+/-8.80 \mathrm{~cm}$, respectively. Kinare et al. (2010) in their study from Pune, India measured HC and BPD by ultrasound in 653 singleton pregnancies and they found that $\mathrm{HC}$ of fetuses in their study was comparable to that of French reference at 18 and 36 weeks of gestation; BPD in Indian fetuses was smaller than French reference for same GA. The study stressed that Indian fetuses were smaller then French counterpart [17]; however, Warrier and Ashokan (2016) found HC to be less in Indian fetuses as compared to 
western population for respective GA. HC may vary across different races and following criteria of western population can result in inaccurate GA estimation and microcephaly [4].

Natale and Rajagopalan (2014) in their study compared growth parameters among economically advantage children across 55 countries and compared it with WHO's Multicentre Growth Reference Study (MGRS). They found marked difference in $\mathrm{HC}$ among national and ethnic group and following WHO set of reference growth curve chart can lead to misdiagnosis of many children having microcephaly or macrocephaly. Hence use of single $\mathrm{HC}$ reference is not justified [3].

The study reflects that both $\mathrm{HC}$ and BPD shows linear increase with increase in GA and $\mathrm{HC}$ to be nearly equal to that of Hadlock's HC and BPD to be lower than Hadlock's BPD. Study is limited by number of representative fetuses of different GA, requiring larger studies for findings to be clinically useful.

\section{CONCLUSION}

$\mathrm{HC}$ and BPD are important marker for estimation of GA and fetal growth monitoring. Western based data are often used but different racial, geographical and ethnical factor and nutritional factors leads to different BPD and HC. This study had shown that while $\mathrm{HC}$ is nearly equal to Hadlock's reference, BPD was less than Hadlock's for GA, reflecting need of local reference data for accurate fetal age estimation and growth monitoring.

\section{REFERENCES}

1. Schwarzler P, Bland JM, Holden D, Campbell S, Ville Y. Sex-specific antenatal reference growth charts for uncomplicated singleton pregnancies at 15-40 weeks of gestation. Ultrasound Obstet Gynecol. 2004;23:23-9.

2. Hiwale SS, Misra H, Ulman S. Ultrasonography-based fetal weight estimation: Finding an appropriate model for an Indian population. Journal of Medical Ultrasound. 2017;25(1):24-32.

3. Natale V, Rajagopalan A. Worldwide variation in human growth and the World Health Organization growth standards: a systematic review. BMJ Open. 2014;4(1):e003735.

4. Warrier HG, Ashokan KM. Fetal biometry in late 3rd trimester for gestational age Indian standards. Int J Sci Stud. 2016;3(12):295-298.

5. Jaiswal P, Masih WF, Jaiswal S, Chowdhary DS. Assessment of fetal gestational age by ultrasonic measurement of bi-parietal diameter in the southern part of Rajasthan. Med J DY Patil Univ. 2015;8:27-30.

6. https://www.cdc.gov/zika/pdfs/microcephaly measuring.pdf

7. Hadlock FP, Deter RL, Harrist RB, Park SK. Estimating fetal age: computer-assisted analysis of multiple fetal growth parameters. Radiology. 1984;152(2):497-501.

8. Menounou A. Head size: Is it important? Advances in Clinical Neuroscience and Rehabilitation. 2011;11(2):16-20.

9. Davies DP, Senior N, Cole G, Blass D, Simpson K. Size at birth of Asian and White Caucasian babies born in Leicester: implications for obstetric and paediatric practices. Early Human Development. 1982;3(6):257-263.

10. Sachdev HPS. Low birthweight in South Asia. In: Gillespie S, ed. Malnutrition in South Asia; A Regional Profile. UNICEF; 1997.

11. Yajnik CS, Fall CH, Coyaji KJ, Hirve SS, Rao S, Barker DJ et al. Neonatal anthropometry: the thin-fat Indian baby. The Pune Maternal Nutrition Study. Int $\mathrm{J}$ Obes Relat Metab Disord. 2003;27(2):173-180. 
12. Deloison B, Chalouhi GE, Bernard JP, Ville Y, Salomon LJ. Outcomes of fetuses with small head circumference on second trimester ultrasonography. Prenatal Diagnosis. 2012;32:869874.

13. Stulp G, Verhulst S, Pollet TV, Nettle D, Buunk AP. Parental height differences predict the need for an emergency caesarean section. PLoS ONE. 2011;6(6):e20497. doi:10.1371/journal.pone.0020497.

14. Elvander C, Hogberg U, Eke'us $C$. The influence of fetal head circumference on labor outcome: a population-based register study. Acta Obstet Gynecol Scand. 2012;91:470-475.

15. Gardberg $M$ et al. Malpresentation-impact on mode of delivery: Acta Obstetricia et Gynecologica Scandinavica. 2011. Nordic Federation of Societies of Obstetrics and Gynecology; 90;540-542.

16. Chan WB, Yeo GS. A comparison of fetal biparietal diameter measurement in local Chinese and Caucasian population. Singapore Med J. 1991;32(4):214-7.

17. Kinare AS, Chinchwadkar MC, Natekar AS et al. Patterns of fetal growth in a rural Indian cohort and a comparison with a western European population, data from the Pune Maternal Nutrition Study. Journal of ultrasound in medicine : official journal of the American Institute of Ultrasound in Medicine. 2010;29(2):215-223. 